\title{
Chronic playback of boat noise does not impact hatching success or post-hatching larval growth and survival in a cichlid fish
}

Anthropogenic (man-made) noise has been shown to have a negative impact on the behaviour and physiology of a range of terrestrial and aquatic animals. However, direct assessments of fitness consequences are rare. Here we examine the effect of additional noise on early life stages in the model cichlid fish, Neolamprologus pulcher. Many fishes use and produce sounds, they are crucial elements of aquatic ecosystems, and there is mounting evidence that they are vulnerable to anthropogenic noise; adult $N$. pulcher have recently been shown to change key behaviours during playback of motor boat noise. Using a split-brood design to eliminate potential genetic effects, we exposed half of the eggs and fry from each clutch to four weeks of playbacks of noise originally recorded from small motor boats with the other half acting as a control (receiving no noise playback). There was no significant effect of additional noise on hatching success or fry survival, length or weight at the end of the exposure period. Although care should be taken not to generalize these findings on a single species from a laboratory study, our data suggest that moderate noise increases do not necessarily have direct negative impacts on early-life survival and growth. Further studies on a range of species in natural conditions are urgently needed to inform conservation efforts and policy decisions about the consequences of anthropogenic noise. 


\title{
1 Chronic playback of boat noise does not impact hatching \\ 2 success or post-hatching larval growth and survival in a \\ 3 cichlid fish
}

\author{
5 Rick Bruintjes ${ }^{1,2}$ and Andrew N. Radford ${ }^{1}$ \\ $6{ }^{1}$ School of Biological Sciences, University of Bristol, Life Sciences Building, 24 Tyndall Avenue, \\ 7 Bristol, BS8 1TQ, United Kingdom \\ $8{ }^{2}$ Biosciences, College of Life and Environmental Sciences, University of Exeter, Stocker Road, \\ 9 Exeter, EX4 4QD, United Kingdom
}

10 Author for correspondence: (rbruintjes@yahoo.com)

11 Running headline: Boat noise does not impact fry survival and growth 


\section{Introduction}

13 Noise-generating human activities, such as transportation, urbanisation and resource exploitation,

14 have altered the acoustic environment in many terrestrial and aquatic environments around the

15 globe (Normandeau Associates Inc. 2012; Watts et al. 2007). Consequently, anthropogenic or

16 man-made noise is now recognised as a pollutant in both national and international legislation

17 (e.g. US National Environment Policy Act and European Commission Marine Strategy

18 Framework Directive). While there is increasing evidence that anthropogenic noise can affect the

19 behaviour and physiology of a wide range of organisms (Barber et al. 2010; Kight \& Swaddle

20 2011; Morley et al. 2014; Slabbekoorn et al. 2010), it is often difficult to translate the obtained

21 findings into ultimate fitness consequences (Morley et al. 2014). What is needed to move forward

22 are studies that use carefully controlled experiments to rule out potential confounding factors,

23 involving repeated or chronic exposure since cumulative effects may alter responses (Bejder et al.

$24 \underline{2009}$ ), and that directly assess reproductive success or survival (Francis \& Barber 2013; Morley

25 et al. 2014).

26 Here we investigate how chronic playback of additional noise, from original recordings of

27 motor boats, affects hatching success and the growth and survival of young in a model fish

28 species Neolamprologus pulcher. Organisms are generally well adapted to tolerate normal

29 environmental fluctuations and challenges early in life (Gilbert 2001; Hamdoun \& Epel 2007)

30 (Hamdoun and Epel 2007), but anthropogenic disturbances can push conditions beyond usual

31 variability. Heavy metals, extreme temperature or $\mathrm{pH}$, and chemical pollutants have all shown to

32 have a negative impact on development (Baradaran-Heravi et al. 2012; Hamlin \& Guillette 2010;

33 Markey et al. 2001). Noise too can be deleterious during development in humans (reviewed in

34 Ising \& Kruppa 2004) and rats (reviewed in Kight \& Swaddle 2011). However, experimental

35 investigations of how anthropogenic noise impacts early-life in other organisms are rare (but see 
36 Banner \& Hyatt 1973; Caiger et al. 2012; McDonald et al. 2014; Nedelec et al. 2014; Wysocki et

37 al. 2007).

38 All fishes studied to date are capable of hearing, with many hundreds known to use and

39 produce sounds (Popper \& Fay 2011; Slabbekoorn et al. 2010), and there is mounting evidence

40 that at least some species are vulnerable to the impacts of anthropogenic noise (Radford et al.

41 2014; Simpson et al. 2014; Slabbekoorn et al. 2010). Small boats are ubiquitous wherever

42 humans live near aquatic environments, and coastal regions are experiencing unprecedented

43 human population growth: densities within $100 \mathrm{~km}$ of the ocean are now three times greater than

44 the global average (Small \& Nicholls 2003). Moreover, aquatic recreation and tourism activities

45 are rapidly rising, with motor boats accounting for a large percentage of boating traffic (see

46 Whitfield \& Becker 2014). Recent studies have demonstrated that motor boat noise can affect the

47 behaviour and physiology of various fish species (Bruintjes \& Radford 2013; Graham \& Cooke

48 2008; Holles et al. 2013; Picciulin et al. 2010; Radford et al. 2015; Voellmy et al. 2014a).

$49 \quad$ Neolamprologus pulcher is a group-living fish found all around the shores of Lake

50 Tanganyika, East Africa (Duftner et al. 2007) in depths ranging from 3 to $45 \mathrm{~m}$ (Taborsky \&

51 Limberger 1981), including harbours and other areas with intensive boat traffic. Previous work

52 has shown that adult behaviour of this species is affected by playback of motor boat noise

53 (Bruintjes \& Radford 2013). Combined with their wide use as a model study organism, including

54 numerous field and laboratory studies (e.g. Bruintjes et al. 2011; Bruintjes et al. 2010; Bruintjes

55 \& Taborsky 2008; Bruintjes \& Taborsky 2011; Heg 2008; Zoettl et al. 2013; for a review see

56 Wong \& Balshine 2011), N. pulcher provides an ideal opportunity to conduct controlled

57 experimentation at early life stages. Here, in a laboratory experiment, we split the same clutches

58 between two different sound treatments (playback of recordings of motor boat noise or playback

59 of no noise) and predicted that additional noise would reduce hatching success and growth, as

60 well as increase post-hatching mortality, compared with a quieter control condition. 


\section{Methods}

\section{Ethics Statement}

63 The research carried out followed the Association for the Study of Animal Behaviour Guidelines

64 for the Use of Animals in Research. The University of Bristol Ethical Committee (University

65 Investigator Number: UB/10/034) approved all procedures and all effort was made to minimize

66 suffering.

\section{Study Animals and Husbandry}

68 Groups of three N. pulcher (a dominant pair and one subordinate) were housed in separate 701

69 aquaria (size: $71 \times 38 \times 30 \mathrm{~cm}$ ) at the University of Bristol, U.K. and allowed to breed (see

70 Bruintjes \& Radford 2013). To minimize noise levels, the aquaria were placed on $9 \mathrm{~mm}$ thick

71 insulation material (Acoustalay 250), external water filters were used (Eheim Ecco 2032) with

72 their inlets placed underneath the water surface, and all aquaria bottoms were covered with a

73 layer of sand ( $3 \mathrm{~cm}, 1 \mathrm{~mm}$ grain size). The aquaria contained two flower-pot halves (diameter 10

$74 \mathrm{~cm}$ ) that served as breeding substrate and shelter, and an opaque partition behind which a water

75 heater was placed (Rena smart heater, $100 \mathrm{~W}$ ). All fish were fed with TetraMin flake food (five

76 times/week), frozen bloodworms (once/week; www.ccmoore.com) and ZM-300 food (once/week;

77 zmsystems.co.uk). Water temperature was kept at $27 \pm 0.1^{\circ} \mathrm{C}$ and water quality was kept constant.

78 The presence of eggs was checked for every $1-2$ days in the morning (at $27^{\circ} \mathrm{C}, N$. pulcher eggs

79 take about three days to hatch; Taborsky et al. 2007). 


\section{Experimental Design}

81 Eleven groups produced 20 clutches (1-3 per group) during the three month period of the

82 experiment. One day after laying, eggs were counted and the clutch was randomly assigned to

83 receive four weeks of sound treatment (see Playback Files) starting at one of two times. Playback

84 started either (a) immediately, and thus during both the egg- and fry stages $(n=10)$, or (b) two

85 days post-hatching, and thus during the fry stage only $(n=10)$. Half of each clutch was assigned to

86 one of two breeding containers, one for each sound treatment, and reared in standard conditions

87 without parental care. The breeding containers (size: $13.5 \times 13.5 \times 14 \mathrm{~cm}$ ) were made of thin

88 plastic $(0.3 \mathrm{~mm})$ with a fine mesh at the bottom (mesh size $0.5 \mathrm{~mm}$ ) to ensure aeration and

89 provided ample space for all eggs and fry. Each container was placed in a separate aquarium,

90 with four aquaria used for the control treatment (no additional noise) and four for the additional-

91 noise treatment.

Each aquarium was fitted with an Aqua30, DNH underwater speaker playing either no

93 sound (control treatment) or five randomly chosen $1 \mathrm{~h}$ files of noise derived from original

94 recordings of motor boats (additional-noise treatment) at random hours each day during the $13 \mathrm{~h}$

95 light period of the light:dark cycle (see Figure 1 for spectral level densities and Table 1 for details

96 of the recordings). This intermittent additional-noise regime was chosen because (1) current

97 evidence shows that non-predictable stressors, such as noise, have a stronger effect than

98 predictable (continuous) stressors (e.g. Wright et al. 2007), and (2) anthropogenic noise is

99 typically sporadic in Lake Tanganyika (Bruintjes, personal observation). All 701 aquaria (same

100 dimensions as above) for rearing the eggs and fry had similar water quality and water

101 temperature. Eggs and fry were checked daily to establish hatching success and to remove dead

102 eggs and fry; all eggs were removed three days after the first egg had hatched. Fry were fed ad

103 libitum with fry food (ZM-300; ZM Fish Food, UK). 
105 control and additional-noise playback during the egg stage; fry survival was determined at the 106 end of sound treatment for all clutches. Surviving fry were photographed with a known size

107 reference to determine total length using tpsDig 2.16 software. They were then sacrificed and

108 dried for $36 \mathrm{~h}$ at $70^{\circ} \mathrm{C}$ on a Petri dish before weighing them to the nearest $0.0001 \mathrm{~g}$ with a 109 precision scale (Mettler AE260, DeltaRange). Between weight measurements, the fry were 110 transferred to a sterile Petri dish to exclude the possibility that debris present in the tank water 111 might have biased our results. Between-measurement error of the weights using the original and 112 new sterile Petri dish was very small $( \pm 0.0088 \%)$ and the mean of the two measurements was 113 used for further analysis. Mean dry weight was calculated by dividing the total dry weight of the 114 surviving fry per clutch per treatment by the number of fry. Mean fry length was calculated by 115 averaging the length of the surviving fry per clutch per treatment.

\section{Playback Files}

117 Original recordings of motor boats were made in Bristol harbour (U.K.) during the passing of 118 boats of similar size and with similar engines as found in the harbour of Mpulungu, Lake

119 Tanganyika, Zambia (Table 1); see also (Bruintjes \& Radford 2013). Recordings were made with

120 an omnidirectional hydrophone (HiTech HTI 96-MIN with inbuilt preamplifier; manufacturer

121 calibrated sensitivity $-164.3 \mathrm{~dB}$ re $1 \mathrm{~V} / \mu \mathrm{Pa}$; frequency range $2-30,000 \mathrm{~Hz}$ ) and a recorder

122 (Roland Edirol R09HR; 24-bit; sampling rate $44.1 \mathrm{kHz}$; calibrated using a single reference of 123 known amplitude). All acoustical analyses were done with Avisoft-SASLab Pro software version

124 5.1.17 (Avisoft Bioacoustics, Berlin, Germany). Ten different 15 min sound files were created 125 using three randomly chosen boat passes from a pool of 17 recordings (mean \pm SE duration of 126 boat passing $=18 \pm 3 \mathrm{~s}$, using two boat passes per minute). Following this, the $15 \mathrm{~min}$ files were 
127 used to create one-hour playback tracks, five of which were played back in the additional-noise

128 treatment aquaria per day. The recordings were lowpass filtered at $2 \mathrm{kHz}$ to minimize resonant

129 frequencies (Batty 1989), and highpass filtered at $100 \mathrm{~Hz}$ to play within the frequency range of

130 the speaker (see below).

131 The tracks were played back in the experimental aquaria using a laptop computer with an

132 external soundcard (Roland Edirol UA-1EX), an underwater speaker (Aqua30; DNH; effective

133 frequency range $80-20,000 \mathrm{~Hz}$ ) and were re-recorded in the centre of the aquarium. The sound

134 levels of the individual recordings were adjusted to create files of approximately equal spectral

135 level densities and the recorded tracks were modified so that they were within $5 \mathrm{~dB}$ re $1 \mu \mathrm{Pa}$ root

136 mean square (RMS) of one another. The files were adjusted to play at $127 \mathrm{~dB}$ re $1 \mu \mathrm{Pa}$ RMS

137 (mean \pm S.E.: $127.2 \pm 0.5 \mathrm{~dB}$ re $1 \mu \mathrm{Pa}$ ), calculated over the loudest 2 s per playback. An example

138 of the spectral level densities of the recordings in the field and in the aquaria is given in Figure 1.

\section{Statistics}

140 Statistical analyses were performed on all 20 clutches and on the first clutches per pair $(\mathrm{n}=11)$

141 with PSAW 18.0.0, using proportions for hatching success and survival, and means per clutch for

142 length and weight (see Table 2 for individual sample sizes; length data are missing for one

143 clutch). Linear Mixed Models (LMMs) with REML variance component estimation were used to

144 control for repeated measures as multiple clutches were laid by most groups. In all analyses,

145 'sound treatment' (additional-noise or control) was considered as a fixed factor and for fry

146 survival, length and weight, we also controlled for fixed factor 'exposure start time' (during the

147 egg or fry stage), since those exposed only post-hatching were older at assessment; the interaction

148 term between sound treatment and exposure start time was never found to be significant, and not 
149 reported in the Results. As random factors, where appropriate, clutch number, group and clutch 150 number nested within group were included.

\section{Results}

152 Hatching success was not significantly affected by sound treatment $\left(\mathrm{LMM}: \mathrm{F}_{1,9}=0.44, \mathrm{p}=0.838\right.$;

153 Figure $2 \mathrm{a})$. After controlling for exposure start time $\left(\mathrm{F}_{1,18}=8.13, \mathrm{p}=0.011\right)$, fry survival was not

154 significantly affected by sound treatment when considering all 20 clutches $\left(\mathrm{F}_{1,18}=0.13, \mathrm{p}=0.724\right.$;

155 lower fry survival in the additional-noise treatment in eight cases; lower survival in the control

156 treatment in eight cases; no difference between treatments in four cases). Qualitatively similar

157 results were found when considering only the first clutches per pair (exposure start time:

$158 \mathrm{~F}_{1,9}=8.94, \mathrm{p}=0.015$; sound treatment: $\mathrm{F}_{1,9}=0.31, \mathrm{p}=0.590$; Figure $2 \mathrm{~b}$ ).

159 After controlling for exposure start time (LMM, length: $F_{1,28.9}=10.74, p=0.003$; weight:

$\left.160 \mathrm{~F}_{1,30.7}=16.2, \mathrm{p}<0.001\right)$, sound treatment did not significantly affect either fry length $\left(\mathrm{F}_{1,20.5}=0.78\right.$,

$161 \mathrm{p}=0.388)$ or weight $\left(\mathrm{F}_{1,22.3}=1.08, \mathrm{p}=0.661\right)$ when considering all 20 clutches. Fry in the additional-

162 noise treatment were lighter in six cases and heavier in 10 cases than in the control treatment,

163 while they were shorter in eight cases and longer in seven cases in the additional-noise treatment

164 compared to the control treatment; in the remaining four clutches, no fry survived in at least one

165 of the treatments. When considering only the first clutches per pair, qualitatively similar results

166 were found, with sound treatment not significantly affecting either fry length $\left(\mathrm{F}_{1,13}=0.54\right.$,

$167 \mathrm{p}=0.475$; exposure start time: $\mathrm{F}_{1,13}=0.26, \mathrm{p}=0.616$; Figure $\left.2 \mathrm{c}\right)$ or weight $\left(\mathrm{F}_{1,13}=0.13, \mathrm{p}=0.728\right.$;

168 exposure start time: $\mathrm{F}_{1,13}=0.49, \mathrm{p}=0.497$; Figure $2 \mathrm{~d}$ ). 
170 We found no evidence in our laboratory study using Neolamprologus pulcher that hatching

171 success or fry survival and size four weeks post-hatching were detrimentally affected by chronic

172 exposure to playback of additional noise originating from recordings of small motor boats. These

173 findings are in line with those of Wysocki et al. (2007), who did not detect any significant impact

174 of high continuous aquaculture noise (arising from filters, aeration and water pumps) on the

175 growth or survival of rainbow trout (Oncorhynchus mykiss), but contrast the work of Banner and

176 Hyatt (1973), who reported decreased hatching success and larval growth in fish reared in tanks

177 with high continuous sound-pressure levels from water-pump noise. Our work adds to these

178 previous fish studies by utilising a split-brood design, thus ruling out potential genetic

179 confounding effects, and by considering a sporadic noise source, which may potentially have a

180 greater impact than continuous noise sources of the same intensity (Francis \& Barber 2013;

181 Wright et al. 2007).

182 Using the same sound playbacks, intensity levels and aquaria as in the current study, Bruintjes 183 and Radford (2013) found that additional noise significantly affected the behaviour of $N$. pulcher 184 adults: decreased nest-digging and anti-predator defence was observed, and there were impacts 185 on intra-group aggression levels. One possibility for the apparent lack of response to noise 186 exposure during early life may therefore be that the embryos and fry of this species have yet to 187 develop the hearing capacity to detect the experimental sounds. However, while measurements of

$188 N$. pulcher hearing thresholds at different developmental stages are not available, fry of several 189 fish species are attracted to reef noise (Simpson et al. 2005a) and embryonic coral reef fish 190 respond to noise (Simpson et al. 2005b). It is also unlikely that the early developmental stages are 191 more robust than adults to anthropogenic disturbances (Etzel et al. 1997; Moller \& Swaddle 192 1998). The provision of ad lib food might have buffered the potential effects of noise; reduced 


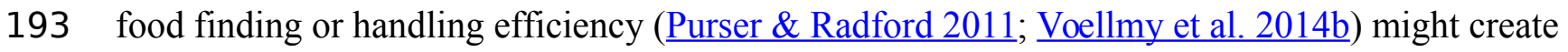

194 negative fitness consequences in natural conditions. It is also possible that there were undetected

195 effects of the additional noise. For instance, the growth trajectories of the fry in the two sound

196 treatments might have differed, especially if responses to noise change with time (Wale et al.

197 2013). Any compensation for initial slow growth could result in consequences for individual

198 fitness (Metcalfe \& Monaghan 2001), but this requires future investigation.

199 Our experiment was performed in aquaria, making it possible to control carefully various 200 potential confounding factors (Slabbekoorn 2015). However, the acoustics of small spaces are 201 complex and are dominated by the particle velocity element of the sound field (e.g. Parvulescu 202 1964). While that might mean that stronger effects would be expected than in natural conditions,

203 field-based studies in the far field and using real noise sources are vital to assess fully the 204 potential impact of anthropogenic noise, especially from the perspective of policy making and 205 management. For now, our results suggest that chronic noise exposure does not necessarily have 206 direct negative impacts on early-life survival and growth (Banner \& Hyatt 1973; Nedelec et al.

207 2014). Studies of the effect on individual fitness are crucial in their own right, as well as forming

208 the basis for assessments about population viability and resilience in the face of anthropogenic 209 change. Given the mixed results from studies investigating the potential impact of noise on early 210 life and development, we advocate further detailed studies in the near future.

\section{Acknowledgements}

212 We are grateful to Markus Zöttl and Michael Taborsky for help importing the fish, Martin Genner 213 for the breeding containers, and Steve Simpson, Julia Purser, Irene Voellmy and Sophie Nedelec 214 for helpful discussions and comments. 
216

217

218

219

220

221

222

223

224

225

226

227

228

229

230

231

232

233

234

235

236

237

238

239

240

241

242

243

244

245

246

247

248

249

250

251

252

253

254

255

256

257
Banner A, and Hyatt M. 1973. Effects of noise on eggs and larvae of two estuarine fishes. Transactions of the American Fisheries Society 1:134136.

Baradaran-Heravi A, Cho KS, Tolhuis B, Sanyal M, Morozova O, Morimoto M, Elizondo LI, Bridgewater D, Lubieniecka J, Beirnes K, Myung C, Leung D, Fam HK, Choi K, Huang Y, Dionis KY, Zonana J, Keller K, Stenzel P, Mayfield C, Luecke T, Bokenkamp A, Marra MA, van Lohuizen M, Lewis DB, Shaw C, and Boerkoel CF. 2012. Penetrance of biallelic SMARCAL1 mutations is associated with environmental and genetic disturbances of gene expression. Human Molecular Genetics 21:2572-2586.

Barber JS, Crooks KR, and Fristrup KM. 2010. The costs of chronic noise exposure for terrestrial organisms. Trends in Ecology \& Evolution 25:180-189.

Batty RS. 1989. Escape responses of herring larvae to visual stimuli. Journal of the Marine Biological Association of the United Kingdom 69:647-654.

Bejder L, Samuels A, Whitehead H, Finn H, and Allen S. 2009. Impact assessment research: use and misuse of habituation, sensitisation and tolerance in describing wildlife responses to anthropogenic stimuli. Marine Ecology Progress Series 395:177-185.

Bruintjes R, Bonfils D, Heg D, and Taborsky M. 2011. Paternity of subordinates raises cooperative effort in cichlids. PLOS ONE 6:e25673.

Bruintjes R, Hekman R, and Taborsky M. 2010. Experimental global food reduction raises resource acquisition costs of brood care helpers and reduces their helping effort. Functional Ecology 24:1054-1063.

Bruintjes R, and Radford AN. 2013. Context-dependent impacts of anthropogenic noise on individual and social behaviour in a cooperatively breeding fish. Animal Behaviour 85:1343-1349.

Bruintjes R, and Taborsky M. 2008. Helpers in a cooperative breeder pay a high price to stay: effects of demand, helper size and sex. Animal Behaviour 75:1843-1850.

Bruintjes R, and Taborsky M. 2011. Size-dependent task specialization in a cooperative cichlid in response to experimental variation of demand. Animal Behaviour 81:387-394.

Caiger PE, Montgomery JC, and Radford CA. 2012. Chronic low-intensity noise exposure affects the hearing thresholds of juvenile snapper. Marine Ecology Progress Series 466:225-232.

Duftner N, Sefc KM, Koblmuller S, Salzburger W, Taborsky M, and Sturmbauer C. 2007. Parallel evolution of facial stripe patterns in the Neolamprologus brichardi/pulcher species complex endemic to Lake Tanganyika. Molecular Phylogenetics and Evolution 45:706-715.

Etzel RA, Balk SJ, Bearer CF, Miller MD, Shea KM, and Simon PR. 1997. Noise: A hazard for the fetus and newborn. Pediatrics 100:724-727. 
258 Francis CD, and Barber JR. 2013. A framework for understanding noise impacts on wildlife: an urgent conservation priority. Frontiers in Ecology and the Environment 11:305-313.

Gilbert SF. 2001. Ecological developmental biology: Developmental biology meets the real world. Developmental Biology 233:1-12.

Graham AL, and Cooke SJ. 2008. The effects of noise disturbance from various recreational boating activities common to inland waters on the cardiac physiology of a freshwater fish, the largemouth bass (Micropterus salmoides). Aquatic Conservation-Marine and Freshwater Ecosystems 18:1315-1324.

Hamdoun A, and Epel D. 2007. Embryo stability and vulnerability in an always changing world. Proceedings of the National Academy of Sciences of the United States of America 104:1745-1750.

Hamlin HJ, and Guillette LJ, Jr. 2010. Birth defects in wildlife: The role of environmental contaminants as inducers of reproductive and developmental dysfunction. Systems Biology in Reproductive Medicine 56:113-121.

Heg D. 2008. Reproductive suppression in female cooperatively breeding cichlids. Biology Letters 4:606-609.

Holles S, Simpson SD, Radford AN, Berten L, and Lecchini D. 2013. Boat noise disrupts orientation behaviour in a coral reef fish. Marine Ecology Progress Series 485:295-300.

Ising $\mathrm{H}$, and Kruppa B. 2004. Health effects caused by noise: evidence in the literature from the past 25 years. Noise \& health 6:5-13.

Kight CR, and Swaddle JP. 2011. How and why environmental noise impacts animals: an integrative, mechanistic review. Ecology Letters 14:10521061.

Markey CM, Luque EH, de Toro MM, Sonnenschein C, and Soto AM. 2001. In utero exposure to bisphenol a alters the development and tissue organization of the mouse mammary gland. Biology of Reproduction 65:1215-1223.

McDonald JI, Wilkens SL, Stanley JA, and Jeffs AG. 2014. Vessel generator noise as a settlement cue for marine biofouling species. Biofouling 30:741-749.

Metcalfe NB, and Monaghan P. 2001. Compensation for a bad start: grow now, pay later? Trends in Ecology \& Evolution 16:254-260.

Moller AP, and Swaddle JP. 1998. Asymmetry, Developmental Stability, and Evolution. Oxford: Oxford University Press.

Morley EL, Jones G, and Radford AN. 2014. The importance of invertebrates when considering the impacts of anthropogenic noise. Proceedings of the Royal Society B-Biological Sciences 281: 20132683.

Nedelec SL, Radford AN, Simpson SD, Nedelec B, Lecchini D, and Mills SZ. 2014. Anthropogenic noise playback impairs embryonic development and increases mortality in a marine invertebrate. Scientific Reports 4:5891.

Normandeau Associates Inc. 2012. Effects of noise on fish, fisheries, and invertebrates in the U.S. Atlantic and Arctic from energy industry sound-generating activities. A literature synthesis for the U.S. Dept. of 
306

307

308

309

310

311

312

313

314

315

316

317

318

319

320

321

322

323

324

325

326

327

328

329

330

331

332

333

334

335

336

337

338

339

340

341

342

343

344

345

346

347

348

349

350

351

352

353

the Interior, Bureau of Ocean Energy Management. Contract \# M11PC00031.

Parvulescu A. 1964. The acoustics of small tanks. In: Tavolga WN, ed. Marine Bioacoustics. Oxford: Pergamon Press, 7-14.

Picciulin M, Sebastianutto L, Codarin A, Farina A, and Ferrero EA. 2010. In situ behavioural responses to boat noise exposure of Gobius cruentatus (Gmelin, 1789; fam. Gobiidae) and Chromis chromis (Linnaeus, 1758; fam. Pomacentridae) living in a Marine Protected Area. Journal of Experimental Marine Biology and Ecology 386:125-132.

Popper AN, and Fay RR. 2011. Rethinking sound detection by fishes. Hearing Research 273:25-36.

Purser J, and Radford AN. 2011. Acoustic noise induces attention shifts and reduces foraging performance in three-spined sticklebacks (Gasterosteus aculeatus). PLOS ONE 6:e17478.

Radford AN, Kerridge E, and Simpson SD. 2014. Acoustic communication in a noisy world: can fish compete with anthropogenic noise? Behavioral Ecology: Early online.

Radford AN, Purser J, Bruintjes R, Voellmy IK, Everley KA, Wale MA, Holles S, and Simpson SD. 2015. Beyond a Simple Effect: Variable and Changing Responses to Anthropogenic Noise. In: Popper AN, and Hawkins AD, eds. The Effects of Noise on Aquatic Life, II. New York: Springer Science+Business Media. In press.

Simpson SD, Meekan M, Montgomery J, McCauley R, and Jeffs A. 2005a. Homeward sound. Science 308:221-221.

Simpson SD, Radford AN, and Purser J. 2014. Anthropogenic noise compromises antipredator behaviour in European eels. Global Change Biology: $10.1111 / g c b .12685$.

Simpson SD, Yan HY, Wittenrich ML, and Meekan MG. 2005b. Response of embryonic coral reef fishes (Pomacentridae: Amphiprion spp.) to noise. Marine Ecology Progress Series 287:201-208.

Slabbekoorn H. 2015. Aiming for progress in understanding underwater noise impact on fish: complementary need for indoor and outdoor studies. In: Popper AN, and hawkins AD, eds. The Effects of Noise on Aquatic Life, II. New York: Springer Science+Business Media. In press.

Slabbekoorn H, Bouton N, van Opzeeland I, Coers A, ten Cate C, and Popper AN. 2010. A noisy spring: the impact of globally rising underwater sound levels on fish. Trends in Ecology \& Evolution 25:419-427.

Small C, and Nicholls RJ. 2003. A global analysis of human settlement in coastal zones. Journal of Coastal Research 19:584-599.

Taborsky B, Skubic E, and Bruintjes R. 2007. Mothers adjust egg size to helper number in a cooperatively breeding cichlid. Behavioral Ecology 7:652657.

Taborsky M, and Limberger D. 1981. Helpers in fish. Behavioral Ecology and Sociobiology 8:143-145.

Voellmy IK, Purser J, Flynn D, Kennedy P, Simpson SD, and Radford AN. 2014a. Acoustic noise reduces foraging success via different mechanisms in two sympatric fish species. Animal Behaviour 89:191198. 
354 Voellmy IK, Purser J, Simpson SD, and Radford AN. 2014b. Increased noise levels have different impacts on the anti-predator behaviour of two sympatric fish species. PLOS ONE 9:e102946.

Wale MA, Simpson SD, and Radford AN. 2013. Size-dependent physiological responses of shore crabs to single and repeated playback of ship noise. Biology Letters 9:20121194.

Watts RD, Compton RW, McCammon JH, Rich CL, Wright SM, Owens T, and Ouren DS. 2007. Roadless space of the conterminous United States. Science 316:736-738.

Whitfield AK, and Becker A. 2014. Impacts of recreational motorboats on fishes: A review. Marine Pollution Bulletin 83:24-31.

Wong $M$, and Balshine S. 2011. The evolution of cooperative breeding in the African cichlid fish, Neolamprologus pulcher. Biological Reviews 86:511530.

Wright AJ, Soto NA, Baldwin AL, Bateson M, Beale CM, and al. e. 2007. Anthropogenic noise as a stressor in animals: A multidisciplinary perspective. International Journal of Comparative Psychology 20:250273.

Wysocki LE, Davidson JW, III, Smith ME, Frankel AS, Ellison WT, Mazik PM, Popper AN, and Bebak J. 2007. Effects of aquaculture production noise on hearing, growth, and disease resistance of rainbow trout Oncorhynchus mykiss. Aquaculture 272:687-697.

Zoettl M, Heg D, Chervet N, and Taborsky M. 2013. Kinship reduces alloparental care in cooperative cichlids where helpers pay-to-stay. Nature communications 4:1341-1341. 


\section{Table 1 (on next page)}

Boat sizes and engine types.

Data on boat sizes and engine types recorded in Bristol harbour (United Kingdom) and Mpulungu harbour in Lake Tanganyika (Zambia). All passing boats were recorded while cruising at average speed $10-50 \mathrm{~m}$ from the hydrophone. 


\begin{tabular}{|c|c|c|c|}
\hline $\begin{array}{l}\text { Boat } \\
\text { Number }\end{array}$ & Place & $\begin{array}{l}\text { Boat } \\
\text { size }(m)\end{array}$ & Engine \\
\hline 1 & Bristol harbour & 2.0 & Outboard, 50 hp, Yamaha \\
\hline 2 & Bristol harbour & 3.0 & Outboard, $25 \mathrm{hp}$, Mariner \\
\hline 3 & Bristol harbour & 4.5 & Outboard, 50 hp, Yamaha \\
\hline 4 & Bristol harbour & 8.0 & Inboard, $40 \mathrm{hp}$, unknown brand \\
\hline 5 & Bristol harbour & 11.0 & Inboard, $40 \mathrm{hp}$, unknown brand \\
\hline 6 & Bristol harbour & 12.0 & Inboard, $120 \mathrm{hp}$, unknown brand \\
\hline 7 & Bristol harbour & 12.0 & Outboard, 25 hp, Mercury \\
\hline 8 & Bristol harbour & 12.0 & Inboard, $70 \mathrm{hp}$, unknown brand \\
\hline 9 & Bristol harbour & 14.0 & Inboard, 70 hp, Ford Fiesta \\
\hline 10 & Bristol harbour & 14.0 & Inboard, $50 \mathrm{hp}$, Ford fsd marine diesel \\
\hline 11 & Bristol harbour & 14.0 & Inboard, $50 \mathrm{hp}$, unknown brand \\
\hline 12 & Bristol harbour & 15.0 & Inboard, $41 \mathrm{hp}$, Mitsubishi diesel \\
\hline 13 & Bristol harbour & 15.0 & Inboard, $40 \mathrm{hp}$, unknown brand \\
\hline 14 & Bristol harbour & 18.0 & Inboard, $60 \mathrm{hp}$, unknown brand \\
\hline 15 & Bristol harbour & 23.0 & Inboard, $80 \mathrm{hp}$, unknown brand \\
\hline 16 & Bristol harbour & 28.0 & Inboard, $75 \mathrm{hp}$, unknown brand \\
\hline 17 & Bristol harbour & 28.0 & Inboard, $80 \mathrm{hp}$, unknown brand \\
\hline 18 & Mpulungu harbour & 3.5 & Outboard, 25 hp, Mercury \\
\hline 19 & Mpulungu harbour & 20.0 & Inboard, $40 \mathrm{hp}$, unknown brand \\
\hline 20 & Mpulungu harbour & 20.0 & Inboard, $60 \mathrm{hp}$, unknown brand \\
\hline 21 & Mpulungu harbour & 26.0 & Inboard, $40 \mathrm{hp}$, unknown brand \\
\hline
\end{tabular}




\section{Table 2 (on next page)}

Sample sizes.

Individual sample sizes used for analyses of hatching success, survival, and length and weight after four weeks of exposure to additional-noise and control conditions. 


\begin{tabular}{lrrr}
\hline Descriptive data & $\begin{array}{r}\text { Hatching } \\
\text { success }\end{array}$ & $\begin{array}{r}\text { Fry survival } \\
\text { at week 4 }\end{array}$ & $\begin{array}{r}\text { Fry measurements at week 4 } \\
\text { (length \& weight) }\end{array}$ \\
\hline No. of clutches used & 10 & $20^{\mathrm{a}}$ & $20^{\mathrm{a}}$ \\
Total no. eggs or fry & 109 fry & 191 fry & 191 fry survived \\
& hatched out of & survived out of \\
& 237 eggs & 415 eggs & \\
Range of egg or fry no. & $7-34$ eggs; & $7-34$ eggs; & $7-34$ eggs; \\
per clutch & $0-34$ fry & $0-30$ fry & $0-30$ fry \\
\hline
\end{tabular}

$2^{\mathrm{a}}$ In 19 out of 20 clutches at least one fry survived in one or both treatment(s).

$3^{\mathrm{b}}$ Length of one clutch was not taken, resulting in 179 length measurements. 


\section{Figure 1}

Spectral densities of field and tank-based recordings.

Spectral level densities in an experimental aquarium during playback of an additional-noise track (AN aquarium) and playback of no noise as an ambient control condition (Ambient aquarium), as well as the spectral level densities from recordings made in Lake Tanganyika during the passing of a boat (BN lake) and during an ambient condition without additional boat noise (Ambient lake). The spectral level densities were created using Avisoft Saslab pro (FFT analysis: spectral level units, Hann evaluation window, 50\% overlap, FFT size 1024, averaged from a $15 \mathrm{sec}$ sample of each recording, presented are $43 \mathrm{~Hz}$ intervals). 


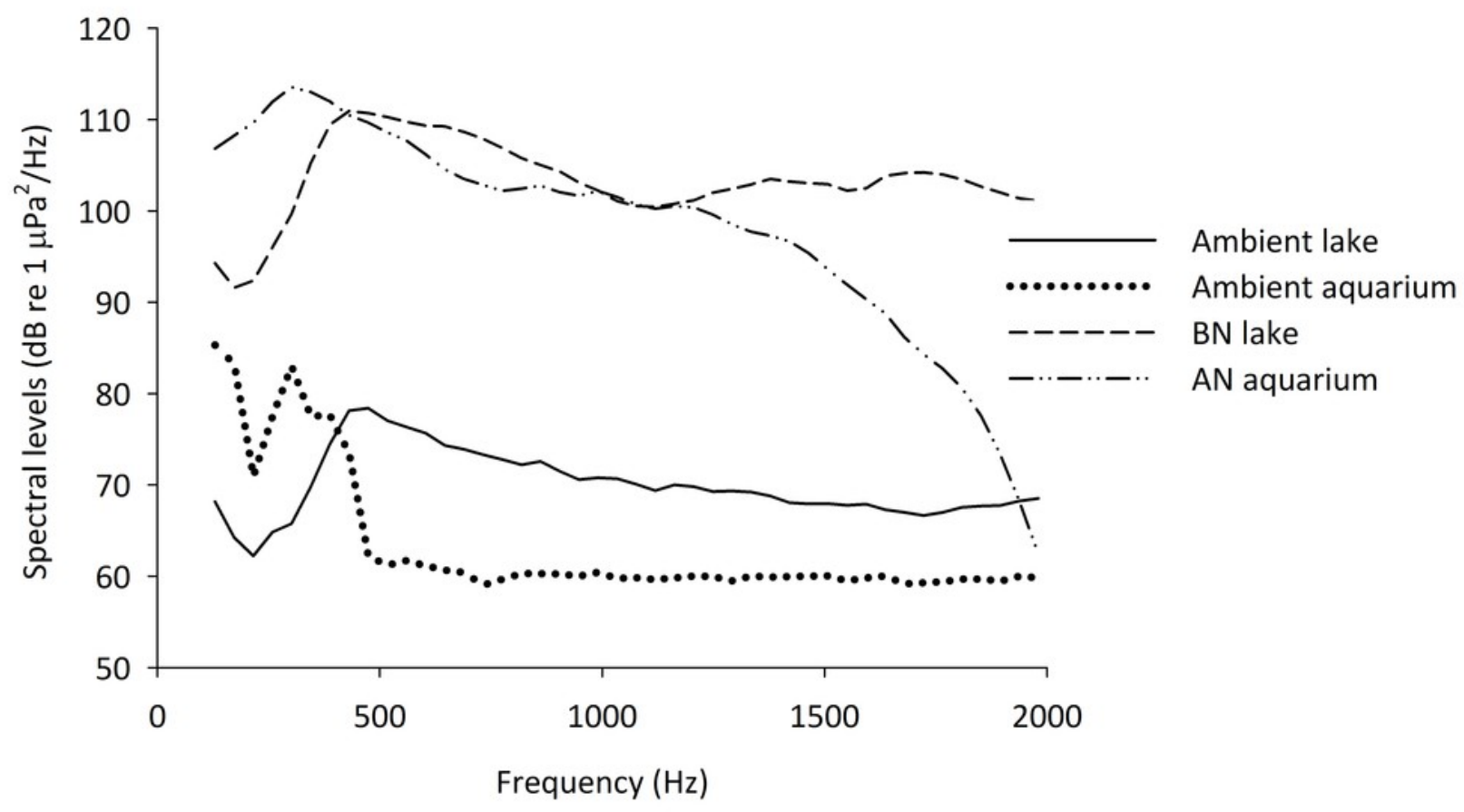




\section{Figure 2}

Hatching success, survival, length and weight at four weeks.

Proportion of clutch that successfully hatched $(n=10)(A)$, proportion of clutch that survived to four weeks $(B)$, mean length of fry at four weeks $(C)$, and mean dry weight of fry at four weeks (D) in the two sound treatments. Presented in (B)-(D) are values from first clutches $(n=11)$, with solid lines representing clutches receiving noise starting during the fry stage and dotted lines clutches receiving noise starting during the egg stage. Four clutches in $(A)$ and one in (B) had no hatching success or survival, but are shown above zero for visualization. In (C) and (D), unconnected ' $x$ ' symbols represent fry surviving in one of the treatments. 
A.

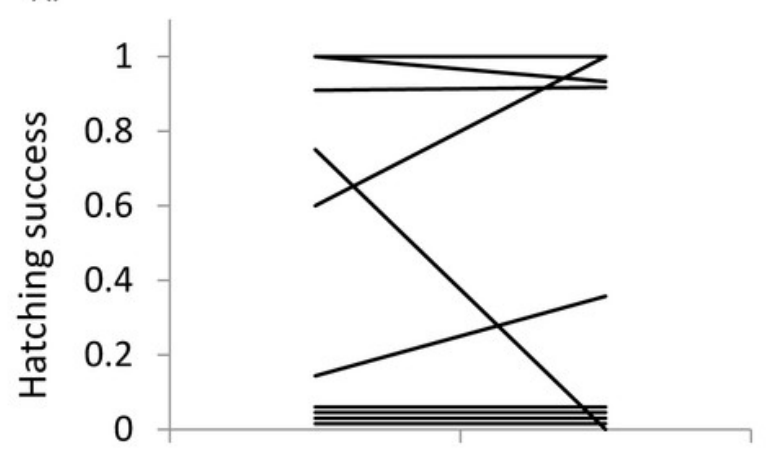

C.

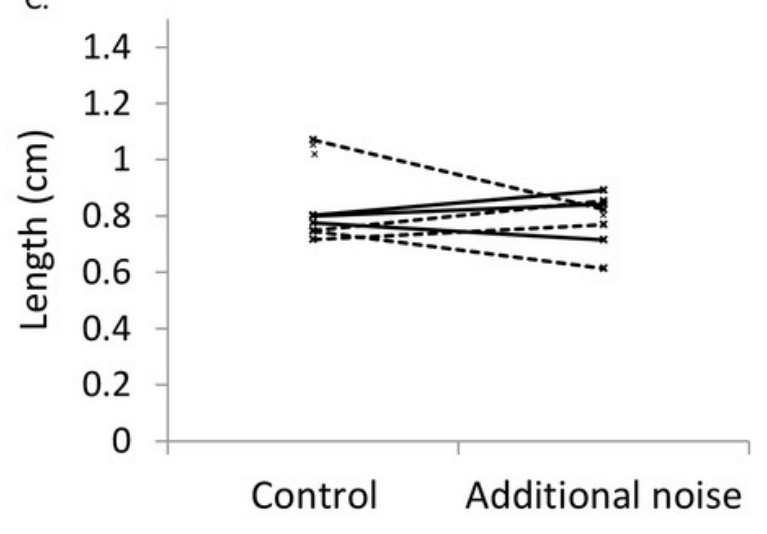

B.

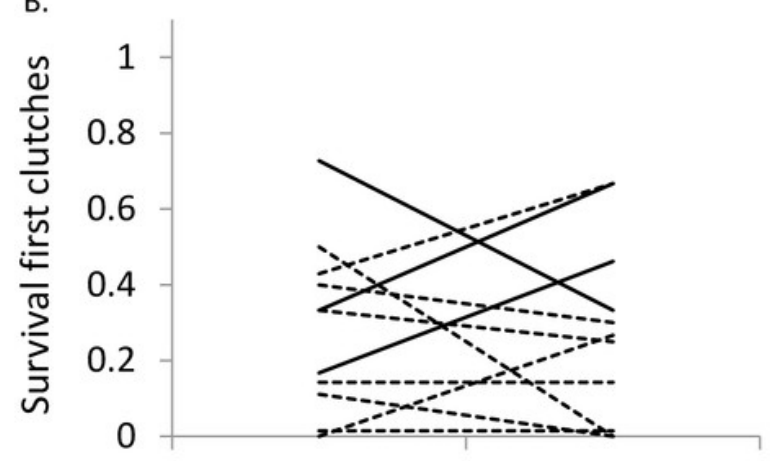

D. 3.5

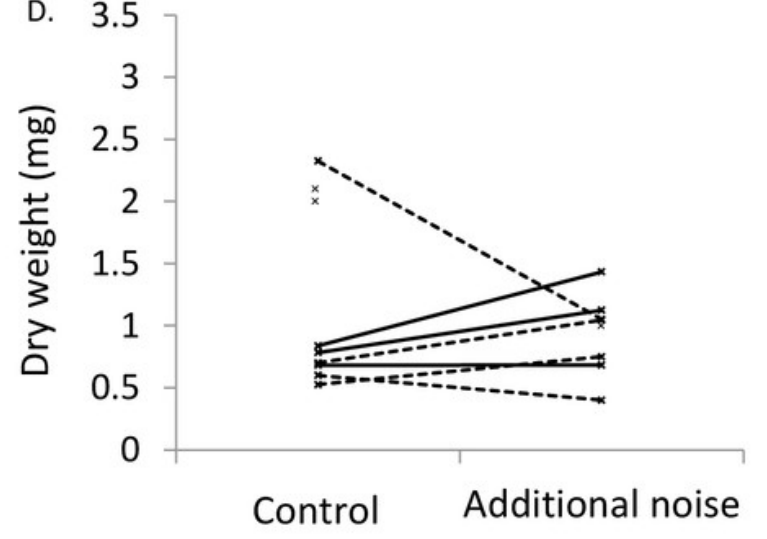

